\title{
Emission Performance of LPG vehicles by Remote Sensing Technique in Hong Kong
}

\author{
Author, co-author (Do NOT enter this information. It will be pulled from participant tab in \\ MyTechZone) \\ Affiliation (Do NOT enter this information. It will be pulled from participant tab in MyTechZone)
}

\begin{abstract}
Since $1^{\text {st }}$ September 2014 the Hong Kong Environmental Protection Department (HKEPD) has been utilising a Dual Remote Sensing technique to monitor the emissions from gasoline and Liquified Petroleum Gas (LPG) vehicles for identifying high emitting vehicles running on road. Remote sensing measures and determines volume ratios of the emission gases of $\mathrm{HC}, \mathrm{CO}$ and $\mathrm{NO}$ against $\mathrm{CO}_{2}$, which are used for determining if a vehicle is a high emitter.

Characterisation of each emission gas is shown and its potential to identify a high emitter is established. The data covers a total of about 2.2 million LPG vehicle emission measurements taken from 14 different remote sensing units. It was collected from $6^{\text {th }}$ January 2012 to $20^{\text {th }}$ April 2017 across a period before and after the launch of the Remote Sensing programme for evaluating the performance of the programme. The results show that the HKEPD Remote Sensing programme is very effective to detect high emitting vehicles and reduce on-road vehicle emissions. The average measured remote sensing emissions of $\mathrm{HC}, \mathrm{CO}$ and $\mathrm{NO}$ reduced by $53.6 \%, 29.6 \%$ and $50.3 \%$ respectively from 2013 (the year before the launch of the programme) to 2015 (the year after the launch of the programme).
\end{abstract}

\section{Introduction}

The effect of localised pollution or smog due to the use of motor vehicles in cities has been well established since the 1960s[1]. Since then emissions controls and regulations have been developed and implemented to improve air quality by reducing the amount of toxic emissions from motor vehicles such as hydrocarbons (HC), carbon monoxide $(\mathrm{CO})$ and nitrogen oxides $\left(\mathrm{NO}_{\mathrm{x}}\right)$. To ensure vehicles comply with the required regulations, monitoring techniques have been developed and applied. Laboratory dynamometer testing of vehicles and engines has been the standard measurement tool for this purpose. These tools whilst reliable and repeatable are not suited to testing a high number of in-use vehicles. The time required for each emissions tests limits the effectiveness of these tools. The need for alternative real world measurement methods has resulted in new techniques being developed for vehicle emissions measurements such as Portable Emissions Measurement System (PEMS), plume chasing, ambient roadside and tunnel measurements[2-4].

The remote sensing techniques to detect the emissions from vehicles as they pass a fixed point has been effectively used to determine if there are instances of high emissions concentrations or excessive fuel consumption from a vehicle fleet. This technique was first developed

Page 1 of 7 and verified in the late 1980's by the University of Denver [5]. The HKEPD has been using remote sensing since 1993 to monitor/survey vehicle emissions. The application of the technique to use as a nonintrusive enforcement tool to detect high emitting vehicles according to relevant emissions regulations has only been in use of recent years. The programme in Hong Kong has been used for enforcement purposes since $1^{\text {st }}$ September 2014 for gasoline and LPG fueled vehicles [6].

The remote sensing technique, utilises light sources to detect specific types of emissions gases: Non Dispersive Infrared for $\mathrm{HC}, \mathrm{CO} \& \mathrm{CO}_{2}$ and Ultraviolet for NO. The light sources are fitted into an instrument which sends the light beams across a lane of traffic to a retro reflector which returns the light beams back to the detector. When a vehicle passes the Remote Sensing instrument the data recording is triggered and the subsequent exhaust plume is measured and values for each of the pollutant gases are recorded. In parallel to this the vehicle speed is measured and a photo of the license plate is recorded by the automatic license plate recognition system for identification purposes. The emission gas values are determined by the reduction or attenuation (due to absorption by the target gases) of the reflected light measured at the detector. The final measurement of the vehicle exhaust plume emissions is calculated from the difference in the ambient concentration measured before the vehicle passes the measurement site and the exhaust plume after the vehicle passes the remote sensing device. To ensure consistency and repeatability of measurement, a second remote sensing device is located approximately one second of driving distance further along the road to repeat the measurement. When both measurements are checked and consistent then the data can be utilised for assessment and enforcement purposes. When not consistent, the data is recorded for survey purposes. This technique is referred to as Dual Remote Sensing and is utilised by HKEPD for vehicle emission survey and policy enforcement purposes.

Vehicles which are identified by the Remote Sensing programme as high emitters are issued with an Emission Testing Notice (ETN) where owner is informed that their vehicle was detected with high emissions and must undergo repairs and then pass chassis dynamometer testing against the Hong Kong Transient Emissions Test (HKTET) within 12 days to remain registered and roadworthy.

Whilst Remote Sensing is able to measure the emissions gas concentrations, the concentrations can vary depending on what section of the exhaust plume is sampled during each individual measurement. The magnitude/volume of the exhaust plume being measured as each vehicle passes Remote Sensing equipment will be variable. Research undertaken by the University of Denver[7, 8] 
indicates the ratios of the pollutant gases in a turbulent exhaust plume can be considered constant. Using this principle, knowing that the major component of the exhaust plume is $\mathrm{CO}_{2}$, ratios of exhaust gases $\mathrm{HC} / \mathrm{CO}_{2}, \mathrm{CO} / \mathrm{CO}_{2}$ and $\mathrm{NOx} / \mathrm{CO}_{2}$ can be utilised to indicate if a vehicle is a possible high polluting vehicle.

With LPG engines running around a stoichiometric Air-Fuel Ratio (AFR), $\mathrm{CO}_{2}$ is measured in the range of 14 to $15 \%$. Using this detail and applying the carbon balance principle, emission factors (EFs) can be calculated by applying the following equations 1-3 [8-11] where $\mathrm{QP}$ is the emission volume ratio of the selected gas divided by $\mathrm{CO}_{2}$ :

$$
\begin{aligned}
& E F_{H C}=\frac{2 \cdot 44}{0.014} \cdot \frac{Q_{H C}}{1+Q_{C O}+6 Q_{H C}}\left[\mathrm{~g} / \mathrm{kg}_{\text {fuel }}\right] \\
& E F_{C O}=\frac{28}{0.014} \cdot \frac{Q_{C O}}{1+Q_{C O}+6 Q_{H C}}\left[\mathrm{~g} / \mathrm{kg}_{\text {fuel }}\right] \\
& E F_{N O}=\frac{30}{0.014} \cdot \frac{Q_{N O}}{1+Q_{C O}+6 Q_{H C}}\left[\mathrm{~g} / \mathrm{kg}_{\text {fuel }}\right]
\end{aligned}
$$

These EF values can be utilised to characterise the on-road vehicle fleet and support the validity of data used for emissions enforcement programmes that maybe undertaken.

Investigations into particular makes or models of vehicles have previously been limited due to the random nature of Remote Sensing measurements. The frequency of measuring the same type of vehicle or having repeat measurements of the same individual vehicle is very low. The exception to this in Hong Kong are the urban LPG taxis. The industry widely adopted the same type of vehicle (i.e. the LPG fueled Toyota Crown Comfort) for use as taxis. This vehicle model makes up $98.9 \%$ of all the urban LPG taxis currently on road in Hong Kong that have been measured by remote sensing. This characteristic of the urban taxi fleet has allowed for a unique opportunity to collect significant amounts of remote sensing data for a single vehicle model.

It is highly desirable to better understand the type of distribution of emissions that can possibly come from a particular vehicle model as it ages so that potential connections between the impacts of vehicle servicing and maintenance, both poor and good can be identified.

\section{Remote Sensing Data Collection Methodology}

Sites for Remote Sensing measurements are selected according to the following criteria[12]. The measurement site should have approximately a $5 \mathrm{~m}$ wide single lane of traffic with a slight uphill gradient so vehicles are under load whilst driving. This should be located away from traffic lights or intersections to avoid off cycle emissions from hard acceleration or deceleration. Traffic volumes should be high, free flowing and the possible vehicle speeds be in the range of 7-90 km/h for repeatable measurements. There should be sufficient space for the Remote Sensing measurement equipment, cameras, staff and the support vehicle to be safely stationed whilst undertaking the measurements. The two Remote Sensing systems are

Page 2 of 7 located with an approximate 1s travel distance between them. When the equipment is in place at the measurement site and power has been connected, it is then able to be warmed up and made ready for measurement. An emissions system check is performed with a puff of reference span gas (specification: High Range BAR-97 with NO $3200 \mathrm{ppm} \mathrm{HC}, 8.0 \% \mathrm{CO}, 12.0 \% \mathrm{CO}_{2} \& 3000 \mathrm{ppm} \mathrm{NO}$ ). This is used to confirm both Remote Sensing units are operating correctly according to the manufacturer specification. The speed measurement system and license plate camera are also checked to be working correctly. During the roadside measurement period the remote sensing equipment is checked with a puff of reference span gas every 2 hours to ensure measurement stability. Figure 1 shows a ETC-S420 remote sensing unit which is used for measurement and Figure 2 shows a typical layout of one of HKEPD's Remote Sensing sites.

If a new measurement site is selected, sufficient sample data must first be collected (thousands of measurements) and reviewed to ensure that site is suitable and to develop a reference measurement profile for vehicle driving behaviour and RSD emissions on the site. When this information has been confirmed, it can be used to validate the location of the RSD equipment onsite and to provide a reference that future measurements can be checked against for validity and stability.

The HKEPD Remote Sensing measurement data used for this study has been collected using 14 remote sensing units. The measurements were collected across 170 sites in Hong Kong. There were 42 sites on Hong Kong Island, 44 sites in Kowloon, 81 sites in the New Territories and 3 on Lantau Island.

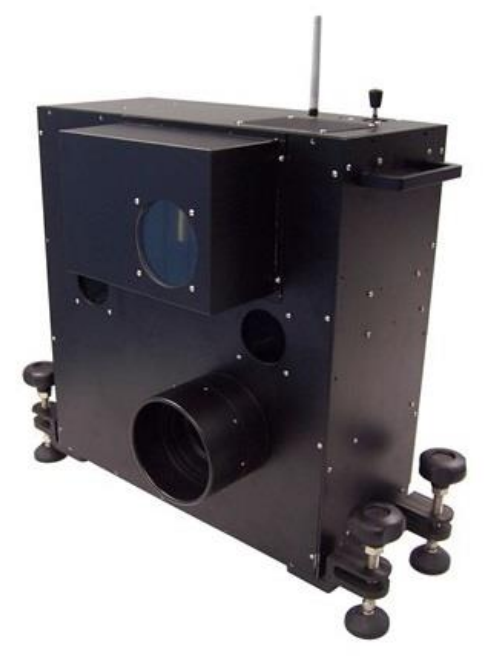

Figure 1. ETC-S420 remote sensing instrument. 


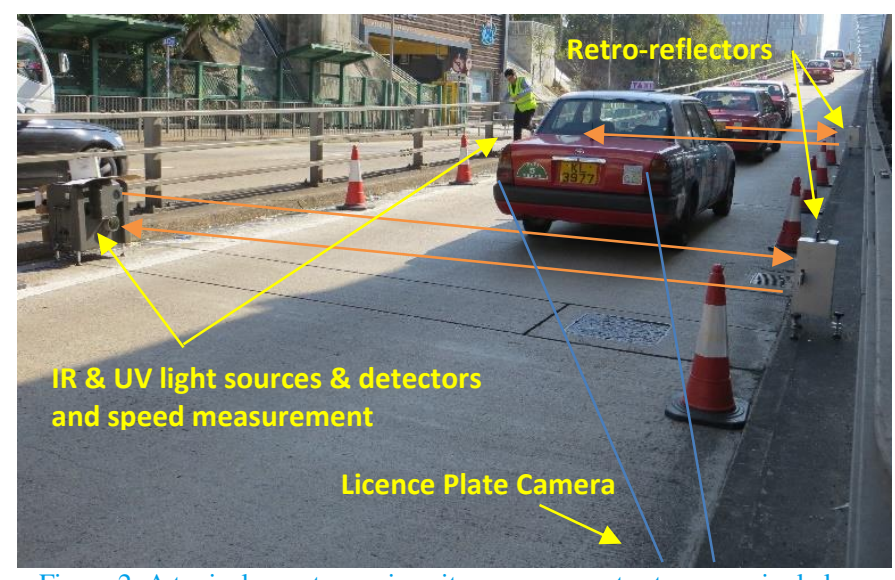

Figure 2. A typical remote sensing site measurement setup on a single lane entry to an arterial road.

\section{Data Characteristics}

The Remote Sensing data was collected between the $6^{\text {th }}$ of January 2012 to $30^{\text {th }}$ of April 2017. There were 2,203,678 measurement records collected for urban LPG fueled taxis during this time. The vehicles measured ranged in year of manufacture from 1997 through to 2016. These records were evaluated to assess if the speed measurement was consistent or there was positive acceleration and that there was sufficient exhaust plume present for analysis. After filtering the data by these criteria there were found to be 763,863 $(34.7 \%)$ valid measurements. Table 1 shows the number and distribution of valid Remote Sensing measurements for taxis taken during the measurement period mentioned above.

Table 1. Number of remote sensing measurement samples and number of vehicles measured in survey year

\begin{tabular}{|c|c|c|c|c|c|c|c|c|c|c|c|c|}
\hline \multirow{2}{*}{$\begin{array}{l}\text { Survey Year } \\
\text { Year of } \\
\text { Manufacture }\end{array}$} & \multicolumn{2}{|c|}{2012} & \multicolumn{2}{|c|}{2013} & \multicolumn{2}{|c|}{2014} & \multicolumn{2}{|c|}{2015} & \multicolumn{2}{|c|}{2016} & \multicolumn{2}{|c|}{2017} \\
\hline & samples & vehicles & samples & vehicles & samples & vehicles & samples & vehicles & samples & vehicles & samples & vehicles \\
\hline 1997 & 3 & 1 & 17 & 1 & 10 & 1 & 9 & 1 & 5 & 1 & 2 & 1 \\
\hline 1999 & 392 & 76 & 858 & 86 & 664 & 79 & 676 & 63 & 525 & 51 & 110 & 28 \\
\hline 2000 & 7849 & 1423 & 17810 & 1683 & 14888 & 1744 & 15586 & 1362 & 10297 & 1016 & 2210 & 571 \\
\hline 2001 & 27840 & 5416 & 70499 & 6441 & 57262 & 6633 & 63885 & 5392 & 46274 & 4328 & 10346 & 2569 \\
\hline 2002 & 7071 & 1413 & 18235 & 1681 & 15736 & 1749 & 21464 & 1687 & 17279 & 1563 & 4399 & 1010 \\
\hline 2003 & 3961 & 777 & 11113 & 952 & 9344 & 993 & 12816 & 950 & 10896 & 921 & 2747 & 654 \\
\hline 2004 & 2432 & 463 & 5911 & 559 & 5612 & 593 & 7231 & 585 & 6328 & 570 & 1803 & 418 \\
\hline 2005 & 1083 & 220 & 2797 & 263 & 2639 & 274 & 3449 & 271 & 3199 & 267 & 848 & 200 \\
\hline 2006 & 1303 & 251 & 3554 & 307 & 3150 & 321 & 4280 & 312 & 3809 & 315 & 972 & 244 \\
\hline 2007 & 1241 & 258 & 3272 & 298 & 2945 & 315 & 4215 & 315 & 3676 & 303 & 933 & 226 \\
\hline 2008 & 1873 & 366 & 4433 & 436 & 4414 & 447 & 6646 & 442 & 5340 & 443 & 1532 & 343 \\
\hline 2010 & 1523 & 291 & 3832 & 340 & 3616 & 352 & 5858 & 354 & 4822 & 348 & 1281 & 284 \\
\hline 2011 & 1464 & 282 & 3656 & 335 & 3397 & 341 & 5300 & 343 & 4677 & 341 & 1243 & 264 \\
\hline 2012 & 162 & 44 & 2270 & 227 & 2575 & 237 & 3921 & 237 & 3459 & 232 & 834 & 185 \\
\hline 2013 & 2 & 1 & 283 & 39 & 3992 & 821 & 15737 & 991 & 13965 & 977 & 3767 & 825 \\
\hline 2014 & & & & & 523 & 220 & 12851 & 953 & 13634 & 975 & 3719 & 843 \\
\hline 2015 & & & & & & & 6449 & 1065 & 24709 & 2111 & 8537 & 1870 \\
\hline 2016 & & & & & & & & & 1428 & 459 & 3588 & 831 \\
\hline Total & 59283 & 11465 & 150715 & 13877 & 132779 & 15355 & 194192 & 15554 & 177246 & 15449 & 49648 & 11540 \\
\hline Fleet coverage* & & $75.2 \%$ & & $91.0 \%$ & & $100.7 \%$ & & $102.0 \%$ & & $101.3 \%$ & & $75.7 \%$ \\
\hline
\end{tabular}

*-Fleet coverage is determined using the number of government issued urban taxi licenses during the survey period, 15250 [13].

\section{Results and Discussion}

\section{Fleet Distribution}

The composition of the urban taxi fleet across the survey years has been identified from the data and is shown above in Table 1.

A significant portion of the fleet surveyed in $2012,78.6 \%$ was from the manufacture years 2000 to 2003 . The 2001 manufacture year comprised $47.2 \%$ of all surveyed vehicles in this year. The fleet composition remained similar in 2013 and started to change in 2014. By 2017 the new vehicles from 2014 to 2017 comprised $37.9 \%$ of the Page 3 of 7 taxi fleet. The corresponding reductions were in the 2000 to 2003 vehicle manufacture years. By 2017 the 2001 model was still the largest single segment of the fleet but has reduced to $22.3 \%$ of the total fleet.

The fleet composition influences the impact of average emissions values and calculated EFs significantly. In the survey years 2012 and 2013 the highest emissions contribution to the average levels are from the 2000 to 2003 model years. As government programmes came into effect [14], firstly a one off LPG vehicle new emissions catalyst and oxygen sensor replacement programme in 2013 to 2014 and then the introduction of Remote Sensing enforcement on the $1^{\text {st }}$ of September 
2014, the emissions from the fleet and its composition began to change. The impact of the emissions catalyst and oxygen sensor replacement programme reduced the emissions from older taxis significantly in 2014 and 2015. Further to this renewal rate of the taxi fleet began to increase from some 267 vehicles in 2012 [15] to 1940 vehicles in 2015, an increase of over $700 \%$ in the fleet renewal rate. The renewal rate has reduced to 1534 in 2015 and 1652 in 2016 [13].

In the years from 2003 to 2014 the LPG urban taxi fleet renewal rates were very low as LPG taxis were originally introduced into Hong Kong en masse with the support of a government incentive programme to replace 'dirtier' diesel taxis with 'cleaner' LPG taxis from 2000 to 2003 [16]. Since September 2014 all LPG taxis have been subject to the remote sensing enforcement programme. The older taxis if they are identified as a high emitter will be issued with an ETN, must be repaired and pass the required HKTET so they can remain in service. With normal wear and tear and the additional maintenance costs, the industry is identifying that the older vehicles are reaching the end of their service life and as the Hong Kong Transport Department registration data shows they are progressively being replaced at a higher rate.

\section{Emissions Trends}

Initial data analysis selected measurement records with both valid speed and gas criteria. Grouping the records into survey year provides fleet average trend information on the emissions concentrations of $\mathrm{HC}$, $\mathrm{CO}$ and NOx for each given year. This shows a general trend of decreasing emissions concentrations of the pollutants $\mathrm{HC}, \mathrm{CO}$ and NOx. The data is summarised in Table 2.

Table 2. Fleet average emissions concentrations measured by remote sensing for each survey year

\begin{tabular}{cccc}
\hline Ave. conc. & $\begin{array}{c}\text { HC } \\
(\mathbf{p p m})\end{array}$ & $\begin{array}{c}\text { CO } \\
(\mathbf{\%})\end{array}$ & $\begin{array}{c}\text { NOx } \\
(\mathbf{p p m})\end{array}$ \\
\hline $\mathbf{2 0 1 2}$ & 256.5 & 0.648 & 1708.1 \\
$\mathbf{2 0 1 3}$ & 223.5 & 0.515 & 1436.3 \\
$\mathbf{2 0 1 4}$ & 137.8 & 0.355 & 820.7 \\
$\mathbf{2 0 1 5}$ & 116.0 & 0.371 & 616.0 \\
$\mathbf{2 0 1 6}$ & 126.3 & 0.395 & 607.6 \\
$\mathbf{2 0 1 7}$ & 110.4 & 0.419 & 502.7 \\
\hline
\end{tabular}

For HC and NOx the fleet trends show total average emissions concentration decreases of $57.1 \%$ and $70.6 \%$ respectively. Whilst CO initially decreases from 2012 to 2014 by $44.6 \%$, it then increases from 2015 to 2017 by $16.7 \%$. During the overall survey period the fleet trend for average emissions for CO decreases by $35.4 \%$.

If we consider the possible impact of the Remote Sensing programme, the average emissions for $\mathrm{HC}, \mathrm{CO}$ and $\mathrm{NO}$ have been reduced by $53.6 \%, 29.6 \%$ and $50.3 \%$ respectively from 2013 to 2015 . Whilst remote sensing has been responsible for identifying the high emitters in this period so they can be targeted for repair or removal from the urban taxi fleet. It is not the only mechanism responsible for the improvements observed during this period as mentioned earlier.
Further investigation into the measurement results utilised the year of manufacture for each vehicle to consolidate data into discrete year groups to characterise the fleet performance. EFs for each emission data record were calculated and averages plotted as shown in Figures 3- 5. These results have been organized by vehicle year of manufacture and then by survey year. Sample sizes for each individual point are in excess of 100 data records[17] to ensure statistical validity.

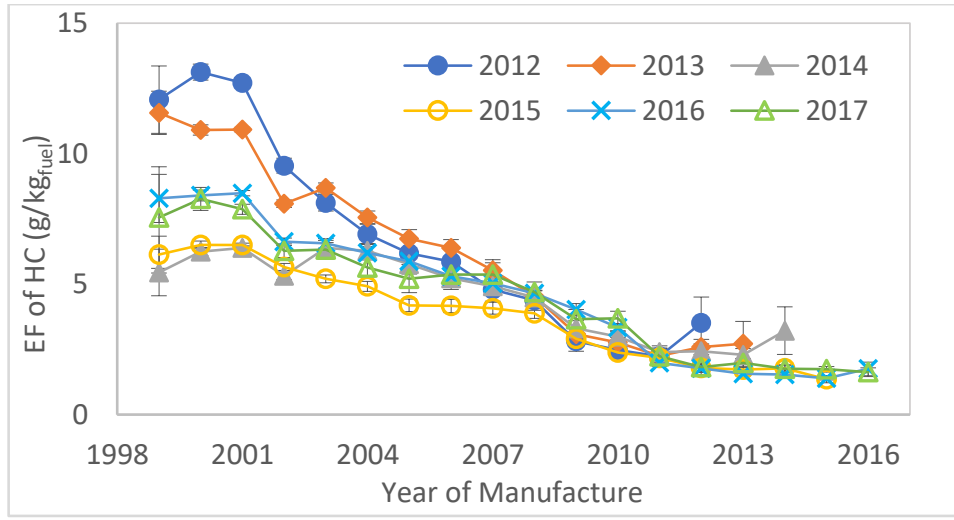

Figure 3. Urban LPG taxi emission factors for HC.

The EF of HC emissions in Figure 3 show an overall decreasing trend from 2012 to 2017. It is noted that vehicles manufactured between 1999 and 2003 show significant decreases in HC emissions from 2012 to 2014, but then are noted to increase to higher levels than other manufacture years in 2015 to 2017. The years of manufacture, 2004 onwards, have the same initial decreases, but only slight increases in HC emission rates from 2015 to 2017 which reflect slight deterioration expected with normal vehicle use and wear.

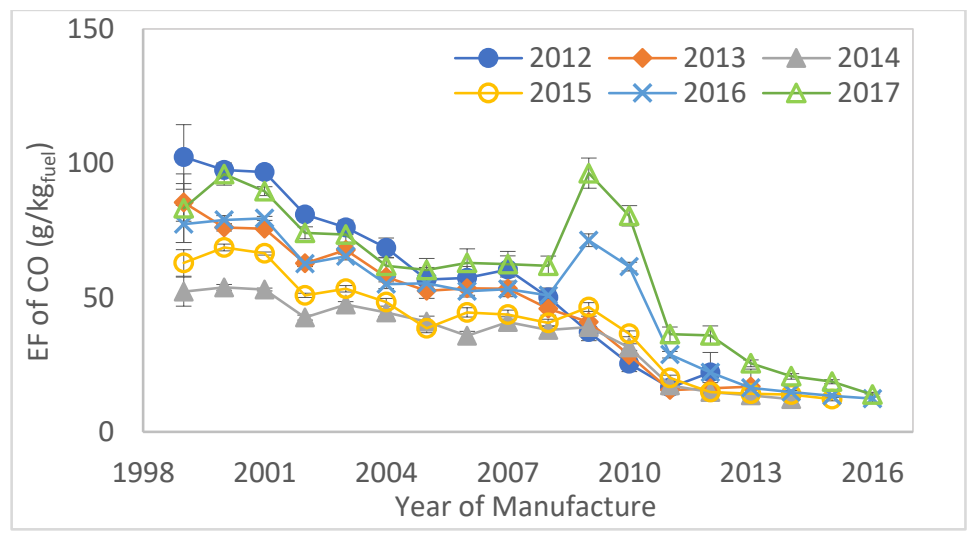

Figure 4. Urban LPG taxi emission factors for CO.

The EF of CO emissions in Figure 4 shows an initial decreasing trend. All of the vehicle manufacture years show significant decreases from 2012 to 2014 and then begin to increase back to comparable levels of the 2012 survey year or higher in 2015 to 2017 . The increase during this period for vehicles manufactured in 2009 and 2010 is substantial and much greater than levels monitored for any other vehicle years. The overall emissions rates would suggest that $\mathrm{CO}$ has deteriorated faster than $\mathrm{HC}$ and could have higher emissions rates in future years than the initial 2012 measurements. 


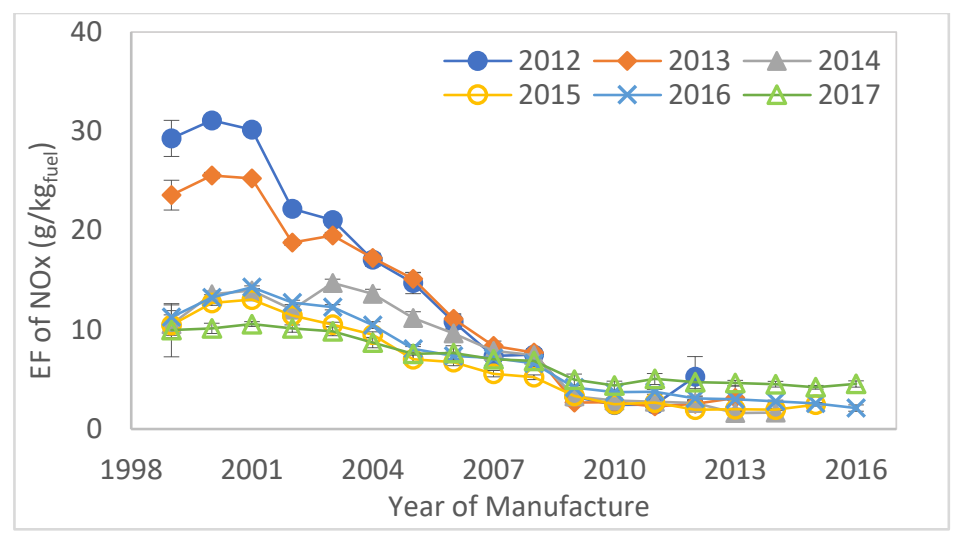

Figure 5. Urban LPG taxi emission factors for NOx. a single vehicle to be measured is 1 and the maximum for 2013, 2014, 2015 and 2016 are 301, 47, 350 and 136 respectively.

In 2012 the Remote Sensing programme was ramping up and did not have as many measurement days. This is reflected in the data from Table 1 with 59283 measurements and $75.2 \%$ of the fleet being measured in 2012. The data for 2017 is for the first four months of the year, 49648 measurements and covering $75.7 \%$ of the fleet. If the measurement rate was maintained then approximately 150,000 measurements could be achieved. Based on this it could be possible to have an average of between 10 to 12 measurements per vehicle with $90 \%$ or higher fleet measurement coverage achieved for 2017.

The data suggests that to achieve a high or near complete urban taxi fleet coverage in Hong Kong the number of valid data measurements needs to be in excess of 130,000 .

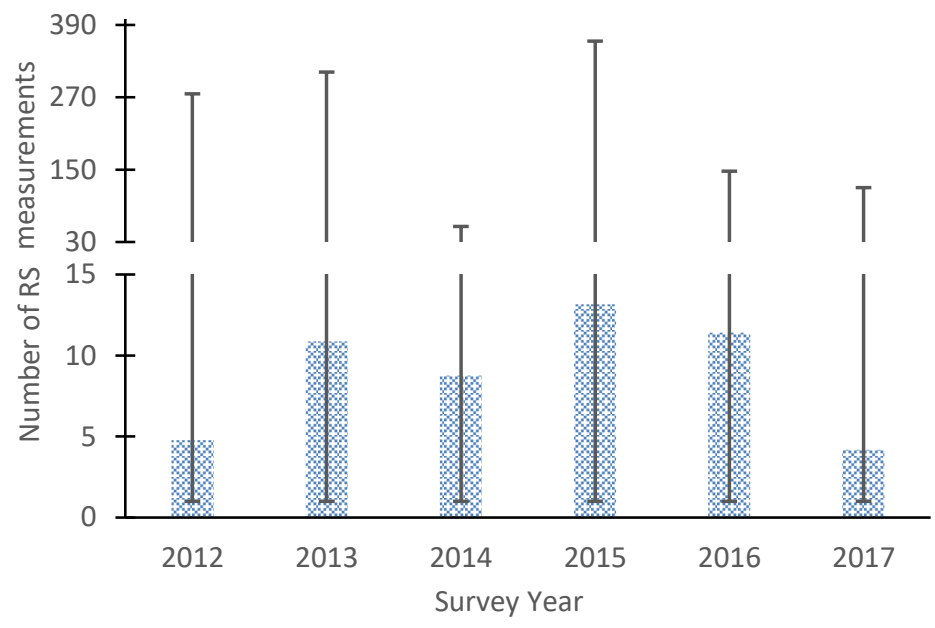

Figure 6. Average number of RS measurements per vehicle in survey year. The blue box represents the average number of measurement per vehicle in the survey year. The black bars indicate the actual minimum and maximum number of RS measurements taken for an individual vehicle in each survey year.

Having a higher average number of measurement per vehicle has improved the percentage of total fleet coverage and increases the likelihood of detection of a vehicle which has become a high emitter.

\section{Conclusions}

The Remote Sensing data initially assessed for this paper consisted of 2,203,678 individual records for LPG fueled urban taxis. After review of the data using valid speed and gas criteria 763,863 measurement records were identified for analysis reported in the present study.

A unique feature of this data is that from 1997 to 2016 one make and model of vehicle (the Toyota Crown Comfort) dominated the taxi fleet with $98.9 \%$ of all the analysed Remote Sensing measurements. In addition, the data appeared to suggest that in three of the six survey years $100 \%$ measurement coverage of the urban taxi fleet was achieved. Further investigation of these figures provided details that the vehicle renewal and taxi license transfers artificially push the number to $100 \%$ or higher. The actual fleet coverage is likely higher than $90 \%$ approaching complete coverage 
The RS survey data covers a more than adequate proportion of the fleet and can provide an accurate reflection of the average emissions values and calculated Emission Factors for the taxi fleet.

Over the Survey period from $6^{\text {th }}$ of January 2012 to $30^{\text {th }}$ of April 2017, the analysis for $\mathrm{HC}$ and NOx fleet trends shows total average emissions concentration decreases of $57.1 \%$ and $70.6 \%$ respectively. Whilst CO initially decreases from 2012 to 2014 by $44.6 \%$, it then increases from 2015 to 2017 by $16.7 \%$ During the survey period the fleet trend for average emissions for $\mathrm{CO}$ decreased by $35.4 \%$.

The data has shown in 2012 an initial image of a vehicle fleet which has not been able to be assessed for compliance with vehicle emissions regulations from an inspection and maintenance point of view. The older vehicles in the 2012 survey year are 9 to 12 years of age show the highest emissions, they make up $78.6 \%$ of the vehicle fleet and dominate the resultant average emissions values and calculated EFs.

From 2013 the influence of a one off government supported maintenance programme to replace emissions catalysts and oxygen sensors and the introduction of the Remote Sensing enforcement programme in September 2014 for identifying high emitters significantly lowered the average emissions values and the subsequent calculated emissions factors. The EF values of $\mathrm{HC}, \mathrm{CO}$ and $\mathrm{NO}$ were reduced by $53.6 \%, 29.6 \%$ and $50.3 \%$ respectively from 2013 to 2015 . The Emissions Factors also show significant improvements in the 2000 to 2003 manufacture year vehicle segment. This is also the largest portion of the taxi fleet at this time. The EFs for manufacture year 2000 to 2003 are noted to have reduced by $25 \%$ to $50 \%$ from survey year 2013 to 2014. These are the largest noted reductions from the data.

From 2014 onwards another factor also begins to influence the fleet values of emissions measurements and EF calculations. Taxi fleet renewal. In 2012 there were 267 new taxis registered, by 2015 this number had increased to 1940 , an increase of $726 \%$ in 2 years. This was a change from $1.7 \%$ to $12.7 \%$ renewal of the fleet in only two years. The subsequent years the new registrations were 1534 in 2015 and 1652 in $2016,(10.1 \%$ and $10.8 \%$ of the fleet renewal).

It is observed that in the years after the government supported maintenance programme the $\mathrm{EFs}$ for $\mathrm{HC}, \mathrm{CO}$ and $\mathrm{NO}$ are increasing, 2015 onwards, as the taxi fleet mileage accumulates. This result is not unexpected as the vehicles emissions control systems become less efficient after 1 or 2 years of high mileage accumulation combined with normal engine wear and tear. The HKEPD RS programme will be able to identify taxis that are exceeding their emissions limit and will issue ETN's to effect repairs and reduce high vehicle emissions.

For the foreseeable future the renewal of the taxi fleet combined with the Remote Sensing enforcement programme should maintain average emissions values and calculated EF's at levels much lower than the 2012 levels initially determined from this data.

Whilst vehicle emissions remain a significant factor impacting our environment daily, the continued support for Remote Sensing enforcement programmes needs to be maintained and further developed to produce new technical solutions and innovations that will allow increased accuracy and measurement reliability as newer emissions standards are implemented. Research into this is ongoing in Hong Kong as the application of these methods looks to be expanded. Remote Sensing technology and application methods provide the data that can allow effective vehicle Inspection and Maintenance programmes to be established or improved with the target of improving our air quality.

\section{References}

1. Haagen-Smit, A.J., Smog control - is it just around the corner. Engineering and Science, 1962. 26(2): p. 9-14.

2. Borken-Kleefeld, J., Guidance note about on-road vehicle emissions remote sensing. 2013, San Francisco/USA: The International Council on Clean Transportation (ICCT). Available at: http://theicct.org/road-vehicleemissionsremote-sensing [Accessed October 13, 2013].

3. Franco, V., M. Kousoulidou, M. Muntean, et al., Road vehicle emission factors development: A review. Atmospheric Environment, 2013. 70: p. 84-97.

4. Ropkins, K., J. Beebe, H. Li, et al., Real-World Vehicle Exhaust Emissions Monitoring: Review and Critical Discussion. Critical Reviews in Environmental Science and Technology, 2009. 39(2): p. 79-152.

5. Stedman, D.H. and G.A. Bishop, Evaluation of A Remote Sensor for Mobile Source CO Emissions. 1990: USA. p. 90.

6. Government, H.K., EPD to strengthen emission control of petrol and LPG vehicles in September, in Article 3743. 2014: Hong Kong. p. 1.

7. Bishop, G.A., J.R. Starkey, A. Ihlenfeldt, et al., IR LongPath Photometry: A Remote Sensing Tool for Automobile Emissions. Analytical Chemistry, 1989. 61(10): p. 671A677A.

8. Daniel, A.B., A.B. Gary, S.S. Ryan, et al., Spectroscopy Applied to On-Road Mobile Source Emissions. Applied Spectroscopy, 2006. 60(5): p. 135A-148A.

9. Pokharel, S.S., G.A. Bishop, and D.H. Stedman, Fuel-Based On-Road Motor Vehicle Emissions Inventory for the Denver Metropolitan Area. 2001.

10. Bishop, G.A. and D.H. Stedman, Measuring the Emissions of Passing Cars. Accounts of Chemical Research, 1996. 29(10): p. 489-495.

11. Bishop, G.A. and D.H. Stedman, FEAT Equations for CO, $H C$ and NO. 2014, Denver University.

12. Huang, Y., B. Organ, J.L. Zhou, et al., Emission measurement of diesel vehicles in Hong Kong through onroad remote sensing: Performance review and identification of high-emitters. Environmental Pollution, 2018. 237: p. 133-142.

13. Department, T., Table 4.1a: Registration and Licensing of Vehicles by Class of Vehicles - Jan 2018, T. Department, Editor. 2018: Hong Kong.

14. Governement, H.K., One-off subsidy to assist vehicle owners to replace the catalytic converters and oxygen sensors of their petrol and liquefied petroleum gas taxis and light buses. 2012: Hong Kong.

15. Department, T., Table4la-Registration and Licensing of Vehicles by Class of Vehicles - Jan 2013, T. Department, Editor. 2013: Hong Kong.

16. Electirical Mechanical Services Department. LPG Vehicle Scheme. accessed 2018-03-13; Available from: https://www.emsd.gov.hk/en/gas safety/lpg vehicle schem e/index.html.

17. Chen, Y. and J. Borken-Kleefeld, NOx Emissions from Diesel Passenger Cars Worsen with Age. Environmental Science \& Technology, 2016. 50(7): p. 3327-3332. 


\section{Contact Information}

Bruce Organ

Email: bruceorgan@vtc.edu.hk

\section{Acknowledgments}

The authors would like to thank the Hong Kong Environmental Protection Department (HKEPD) for providing the Remote Sensing Data for analysis in this study. Authors acknowledge the ownership of the data from HKEPD and used it with permission.

\section{Definitions/Abbreviations}

AFR

CO

$\mathrm{CO2}$

conc.
Air Fuel Ratio

Carbon Monoxide

Carbon Dioxide

concentration
ETN

HC

HKEPD

HKTET

NOx

NDIR

QP

RS

UV
Emissions Test Notice

Hydrocarbons

Hong Kong Environmental Protection Department

Hong Kong Transient Emissions Test

Nitrogen Oxides

Non Dispersive Infrared

Concentration ratio of pollutant $\mathrm{P}$ over $\mathrm{CO}_{2}$

Remote Sensing

Ultraviolet 